\title{
Team-based learning: assessing the impact on anatomy teaching in People's Republic of China
}

This article was published in the following Dove Press journal: Advances in Medical Education and Practice

\author{
Junhao Yan' \\ Xinling Ding ${ }^{2}$ \\ Lili Xiong ${ }^{3}$ \\ E Liu' \\ Yixuan Zhang' \\ Yingjie Luan' \\ Lihua Qin' \\ Changman Zhou' \\ Weiguang Zhang' \\ 'Department of Anatomy and \\ Histology, School of Basic Medical \\ Sciences, Peking University, Beijing \\ 100191, People's Republic of China; \\ 2Department of Anatomy, Chifeng \\ Medical College, Neimenggu \\ 024000, People's Republic of China; \\ ${ }^{3}$ Department of Anatomy, West China \\ School of Basic Medical Sciences \& \\ Forensic Medicine, Sichuan University, \\ Chengdu 61004I, People's Republic \\ of China
}

Correspondence: Weiguang Zhang Department of Anatomy and Histology, School of Basic Medical Sciences, Peking University, No. 38 Xueyuan Road, Haidian District, Beijing I0019I, People's Republic of China

Tel +86 I0 82801466

Fax +86 I0 $8280 \quad 1466$

Email zhangwg@bjmu.edu.cn
Objectives: In this study, the effects of team-based learning (TBL) method on the anatomy course for students in People's Republic of China were assessed.

Methods: The students were randomly divided into the traditional lecture-based teaching group (traditional learning [TL] group, 99 students) and TBL teaching group (98 students). The TBL method required the students to prepare the assigned content in advance and discuss some specific topics in small groups. The test scores and questionnaire were applied to evaluate the effects of the two methods.

Results: The students in TBL group had higher examination scores $(81.70 \pm 8.53$ vs $74.41 \pm 8.27$, $F[1,195]=124.6, p<0.01)$. The ratios of students with excellent $\left(13.27 \%\right.$ vs $9.09 \%, \chi^{2}[1]=4.00$, $p=0.041)$ and good scores $\left(25.51 \%\right.$ vs $\left.16.16 \%, \chi^{2}[1]=4.85, p=0.027\right)$ were markedly increased in the TBL than the TL group, and the ratio of students who had just managed to pass was decreased $\left(17.34 \%\right.$ vs $32.33 \%$ in TL group, $\left.\chi^{2}[1]=5.91, p=0.015\right)$. The students in TBL group significantly achieved some improvement in mutual communication ability $\left(\chi^{2}[1]=7.54, p=0.006\right)$, expression ability $\left(\chi^{2}[1]=4.930, p=0.026\right)$, generalization capacity $\left(\chi^{2}[1]=4.08, p=0.043\right)$, cooperative ability cultivation $\left(\chi^{2}[1]=5.04, p=0.024\right)$, knowledge extension $\left(\chi^{2}[1]=4.50, p=0.034\right)$, and enthusiasm mobilization $\left(\chi^{2}[1]=4.27, p=0.039\right)$.

Conclusion: TBL could improve not only the test scores of the students, but also their study enthusiasm, initiative learning ability, communication ability, and team awareness.

Keywords: anatomy, lecture-based learning, student, team-based learning

\section{Introduction}

The team-based learning (TBL) concept was formally introduced by Larry Michaelsen as an educational modality at a business school in 1970, and this approach has since been adopted by a number of medical educators. ${ }^{1-3}$ TBL is an active learning strategy which can provide opportunity for the students to apply their knowledge through discussions within small groups. Therefore, TBL has showed excellent effects on education in some clinical courses compared with the traditional lecture-based method. ${ }^{4-7}$

The anatomy course is a fundamental and difficult course for medical students. To improve the quality of anatomy education, previous researchers developed some methods, eg, problem-based learning method. ${ }^{8}$ However, our experience indicated that these methods were not effective for the students owing to the variety of educational or social backgrounds in People's Republic of China. The students frequently complained that they had not achieved the learning abilities and had only some anatomical 
knowledge. How to perform active learning and freely apply medical knowledge has been a growing critical concern for the students and their teachers.

Therefore, the aim of this study was to assess the effects of TBL method on anatomy in students, and this was compared with lecture-based learning method. Since the TBL has been shown to be effective in some disciplines, such as in physiology, medical genetics, nursing, and ethics education, ${ }^{9-12}$ in the present study, we hypothesized that the TBL will improve the educational effects on the anatomy course for the students.

\section{Methods}

\section{Study design and participants}

In this study, 197 students from the Medicine School of Chifeng College were recruited. These students were randomly divided into the lecture-based learning group (99 students, traditional learning, TL) and TBL teaching group (98 students). Additionally, each group had the same teaching hours.

The present study has been conducted according to the principles of the Declaration of Helsinki and Title 45, US Code of Federal Regulations, Part 46, Protection of Human Subjects, Revised November 13, 2001. All methods were approved by the Association of Medical Ethics of Peking University Health Science Center.

\section{Study procedure}

\section{The TL method}

Ninety-nine students were educated by the TL method, a teacher-centered theoretical (lecture-based) teaching that was performed according to the teaching program objectives. After completion of teaching, the teachers would reiterate the important and difficult points. Finally, the teachers would make a summary about the teaching content.

Each student in the TL group had an anatomy textbook (borrowed from library or purchased); all the content in the class was found in this anatomy textbook, and so the students could learn the content by themselves. The students were also required pre-read the related content in the anatomy textbook. The students in TL group could also interact with the teachers or peers, and they could freely ask the questions in the class, even during the lecture. After class, they also had opportunities to communicate voluntarily and individually with teachers or peers about medical knowledge. Each student in the class submitted to a test before and after the lecture sessions.

\section{The TBL method}

A week before the class, the content and the TBL procedure were informed to the students. Each group (4-5 students each group, considering the gender and other characteristics) was given handouts for preparation. The students previewed the text independently and answered the questions individually using the resources they needed, such as notes and book. Following this, they were required to discuss the same questions within the group and provide 1 set of answers. The questions were formulated as multiple choices questions with only 1 correct answer. Groups of students practiced the problems on clinical diseases and related anatomical knowledge. Finally, the students filled out the peer evaluation forms for their team members. To check the primary outcome of the class, each of these students also submitted a test before and after the TBL sessions.

\section{Data collection tool}

To accurately evaluate the effects of 2 methods, we applied the following collection tools:

\section{Test score}

The final examination was taken by the students after TBL and TL education, and the total score was 100. All students were required to attend the examination. The scores were graded as excellent (90-100 marks), good (80-89 marks), moderate (70-79 marks), and pass (60-69 marks). Additionally, the number of students at each ranking in the TL and TBL groups was recorded.

\section{Questionnaire}

After being informed the reasons, the students in both TL and TBL groups completed the questionnaire freely. Additionally, the students were required to provide written informed consent to participate in this study. The following items were included in the questionnaire: the student's communication ability (communicating with teachers and classmates about the academic problems), expression ability (interpreting the opinions clearly), generalization ability (formulating general concepts from some clinical cases), collaboration ability (resolving the problems with others), knowledge extension (extension of knowledge from one discipline to another), learning initiative (studying the knowledge voluntarily), and classroom atmosphere (vivid and interactive classroom environment) during the anatomy class (Supplementary materials).

To determinate the face validity of this questionnaire, 3 authors of this study took part in a poll. Through applying corrective feedback, the questionnaire's face validity was confirmed. The attitude of students toward TBL was measured using the questionnaire with 7 items on a 3-point Likert scale 
(including "agree," "disagree," "neither agree nor disagree"). The choices for each item were recorded, and the ratios of "agree" to each item in the TL and TBL groups were analyzed using $\chi^{2}$ test (see "Data analysis" section). Totally, 197 questionnaires were issued and were received (ie, the withdrawing rate $=100 \%$ ). To prevent the students from communicating their opinions with each other, the significance of this study and the risk of such communication was explained. There was no data contamination according to their statements.

\section{Data analysis}

After being tested for homogeneity of variance, the examination scores of the students in TL and TBL groups were analyzed by using one way analysis of variance with the Tukey-Kramer post hoc tests. Additionally, the effect evaluation of 2 methods was performed by using $\chi^{2}$ test. A $p$-value of $<0.05$ was considered significant.

\section{Results}

\section{Comparison of final examination scores}

In the final examination, 5 students in TL group scored excellent (90-100 marks), 13 students were good (80-89 marks), 50 students were moderate (70-79 marks), 32 had passed (60-69 marks). Meanwhile, 13 students in TBL group scored excellent, 25 students were good, 43 students were moderate, and 17 students had passed.

The ratio of students with excellent $(13.27 \%$ vs $9.09 \%$ in TL group, $\left.\chi^{2}[1]=4.00, p=0.041\right)$ and $\operatorname{good}$ scores $(25.51 \%$ vs $16.16 \%$ in TL group, $\chi^{2}[1]=4.85, p=0.027$ ) in the TBL group was markedly increased compared with the TL group. Additionally, the ratio of students in TBL group with a pass score was markedly decreased $(17.34 \%$ vs $32.33 \%$ in TL group, $\left.\chi^{2}[1]=5.91, p=0.015\right)$ compared with the TL group.

Furthermore, the average score in the TBL group was also higher than that in the TL group $(81.70 \pm 8.53$ vs $74.41 \pm 8.27$, $F[1,195]=124.6, p<0.01)$ (Table 1).

\section{Evaluation of students}

Through the questionnaire survey, the ratio of students who thought TBL method could mobilize the learning enthusiasm was $87.76 \%$ (vs $77.78 \%, \chi^{2}[1]=4.27, p=0.039$ compared with TL group); $89.80 \%$ students considered it could extend the knowledge scope (vs $78.79 \%, \chi^{2}[1]=4.50, p=0.034$, compared with TL group), $82.65 \%$ students thought it could cultivate cooperative ability (vs $72.73 \%, \chi^{2}[1]=5.04, p=0.024$, compared with TL group), 79.59\% students deemed that their generalization ability was improved (vs $67.68 \%, \chi^{2}[1]$ $=4.08, p=0.043), 81.63 \%$ students considered that it could
Table I The comparison of average score and characteristics of students in TL and TBL groups

\begin{tabular}{lll}
\hline Samples (N=197) & $\begin{array}{l}\text { TL group (N=99), } \\
(\mathbf{m e a n} \pm \mathbf{S D})\end{array}$ & $\begin{array}{l}\text { TBL group } \\
\mathbf{( N = 9 8 ) , ~ ( m e a n ~} \\
\pm \mathbf{S D})\end{array}$ \\
\hline Average score & $74.41 \pm 8.27$ & $81.70 \pm 8.53^{\mathrm{a}}$ \\
Age (year) & $19 \pm 1.14$ & $19 \pm 1.38$ \\
Gender & & $50(51.02 \%)$ \\
Male & $47(47.48 \%)$ & $48(48.98 \%)$ \\
Female & $52(52.52 \%)$ & First year \\
Medical year & First year &
\end{tabular}

Note: ${ }^{a} p<0.01$ compared with that of TL group.

Abbreviations: TBL, team-based learning; TL, traditional learning.

boost their expression ability (vs $68.69 \%, \chi^{2}[1]=4.930$, $p=0.026), 95.92 \%$ students thought it improved the classroom atmosphere (vs $84.85 \%, \chi^{2}[1]=6.93, p=0.008$ ), and $87.88 \%$ students considered that the communication with teachers was enhanced (vs 71.72\% in TL group, $\chi^{2}[1]=7.54, p=0.006$ ).

\section{Discussion}

In the present study, the TBL method was applied for the anatomy courses administered to the students in People's Republic of China. The results of this study indicated that TBL enhanced the examination scores and the enthusiasm, initiative learning ability, communication ability, and team awareness of these students.

Anatomy is the first medical course undertaken by students in People's Republic of China. In the traditional educational mode, the teachers impart anatomy knowledge in the class and evaluate the teaching effects merely through the scores of final examination. ${ }^{8}$ This method is not sufficient to introduce anatomy knowledge into the clinical courses, as the students passively learn the knowledge and gradually lose enthusiasm.

The TBL teaching concept, formally introduced by Larry Michaelsen, is a new educational mode that contributes to the development of team cooperation among the students. ${ }^{13-15}$ The TBL method can also overcome the shortage of teaching resources in some mountainous area. ${ }^{16-18}$ It is reported that TBL method showed better outcomes than traditional education in some preclinical courses. ${ }^{19,20}$

In this study, we adopted the TBL concept as the principal method to assess the teaching effects on students. ${ }^{13-15,21}$ First, the students previewed the text independently and learned as much as possible from the anatomy books, and then the students were randomly divided into small groups, and the leader of each group managed the whole process. Finally, 
the students were required to resolve some clinical question using the anatomy knowledge gained.

Additionally, based on previous studies, ${ }^{22}$ we designed some clinical cases based on the anatomy textbook and tried to include the questions on major anatomical and clinical knowledge. The results showed that TBL method could significantly improve the examination scores than TL, which is in accordance with the previous studies. ${ }^{21-23}$ Furthermore, our results also indicated that the enthusiasm, initiative learning ability, communication ability, and team awareness of these students were markedly enhanced when using TBL method, as was also reported by others..$^{24,25}$ The ability of TBL method to resolve clinical problems were also reported by others. ${ }^{26}$

In the present study, we used the examination scores and questionnaire to evaluate the effects of TBL method. In fact, there were some other methods also used to assess the TBL's effects. The median precourse and postcourse assessment scores were also used by others. ${ }^{27}$ Furthermore, individual readiness assurance test, the group readiness assurance test, and the group application problem have also been applied to evaluate the effects of TBL. ${ }^{28}$

There were some limitations of this study. First, similar to the previous studies, ${ }^{27,28}$ the relatively small sample size (totally 197 students) in this study limited the statistical power and weakened the significance of this study. Second, there was possibility that the students might have communicated their opinions with each other, which might have led to exchange of the information between 2 groups. To reduce this risk, based on the previous experience, ${ }^{29}$ the significance of the study and the risk of communicating opinions with others was explained to them. There was no data contamination according to their statements. Third, the students in the TBL group might have known that they underwent an additional assignment, and thus the self-rated improvement in this study might be biased. To control this bias, we requested them to be fair because these results were just used for research not for grading. In addition, they were assured of the confidentiality of the data. Fourth, there were some subjective indexes in this study (eg, ability improvement). Although our results were encouraging, more objective evidence in medical education is required to verify the effectiveness of TBL method, as reported by the others. ${ }^{21}$ Lastly, in this study, the students were not simultaneously exposed to both TBL and TL, but others have reported this method. ${ }^{30}$ In the future, the selfcontrol study (eg, firstly adopt the TL method and then TBL method) might provide further evidence for the application of TBL method in medical education.

\section{Conclusion}

The present exploration of TBL method in anatomy teaching revealed that this method could improve not only the test scores of the students but also their study enthusiasm, initiative learning ability, communication ability, and team awareness. We believe that TBL is an effective and highly rated innovative learning method in basic medical sciences. This will lead more universities in world to adopt it and provide more active learning and deeper understanding of the basic medical sciences for the medical students.

\section{Acknowledgment}

We thank Professor Ruimao Zheng from Harvard University for refining the English writing in this work.

\section{Disclosure}

The authors report no conflicts of interest in this work.

\section{References}

1. Miles JM, Larson KL, Swanson M. Team-based learning in a community health nursing course: improving academic outcomes. J Nurs Educ. 2017;56(7):425-429.

2. Doshi NP. Effectiveness of team-based learning methodology in teaching transfusion medicine to medical undergraduates in third semester: a comparative study. Asian J Transfus Sci. 2017;11(2):87-94.

3. Zingone MM, Franks AS, Guirguis AB, George CM, Howard-Thompson A, Heidel RE. Comparing team-based and mixed active-learning methods in an ambulatory care elective course. Am J Pharm Educ. 2010;74(9):160.

4. Bleske BE, Remington TL, Wells TD, et al. Team-based learning to improve learning outcomes in a therapeutics course sequence. Am J Pharm Educ. 2014;78(1):13.

5. Haidet P, O'Malley KJ, Richards B. An initial experience with team learning in medical education. Acad Med. 2002;77(1):40-44.

6. Yasuhara T, Kosano H. Team-based Learning (TBL) brings active and complementary learning-practice and outcomes in pharmacy education. Yakugaku Zasshi. 2014;134(2):169-170.

7. Sutherland S, Bahramifarid N, Jalali A. Team-based learning from theory to practice: faculty reactions to the innovation. Teach Learn Med. 2013;25(3):231-236.

8. Wang J, Zhang W, Qin L, et al. Problem-based learning in regional anatomy education at Peking University. Anat Sci Educ. 2010;3:121-126.

9. Gopalan C, Klann MC. The effect of flipped teaching combined with modified team-based learning on student performance in physiology. Adv Physiol Educ. 2017;41(3):363-367.

10. Ismail NA. Effectiveness of team-based learning in teaching medical genetics to medical undergraduates. Malays J Med Sci. 2016;23(2):73-77.

11. Dearnley C, Rhodes C, Roberts P, Williams P, Prenton S. Team based learning in nursing and midwifery higher education; a systematic review of the evidence for change. Nurse Educ Today. 2017;60:75-83.

12. Ozgonul L, Alimoglu MK. Comparison of lecture and team-based learning in medical ethics education. Nurs Ethics. 2017:969733017731916.

13. Parmelee DX, Michaelsen LK. Team-based learning: it's here and it WORKS. Acad Med. 2010;85(11):1658. 
14. Parmelee DX, Michaelsen LK. Twelve tips for doing effective TeamBased Learning (TBL). Med Teach. 2010;32(2):118-122.

15. Parmelee DX. Team-based learning: moving forward in curriculum innovation: a commentary. Med Teach. 2010;32(2):105-107.

16. Norose T, Ito M, Endo K, Fujimoto T, Moriya H, Murakami M. Introduction of Team-based Learning to the Pharmacy Experiential Practice Course for First-year Pharmacy Students. Yakugaku Zasshi. 2014;134(2):179-183.

17. Ofstad W, Brunner LJ. Team-based learning in pharmacy education. Am J Pharm Educ. 2013;77(4):70.

18. Walters DE. Team-based learning applied to a medicinal chemistry course. Med Princ Pract. 2013;22(1):2-3.

19. Allen RE, Copeland J, Franks AS, Karimi R, McCollum M, Riese DJ, et al. Team-based learning in US colleges and schools of pharmacy. $\mathrm{Am}$ J Pharm Educ. 2013;77(6):115.

20. Brich J. Feasibility, acceptance and impact of team-based learning in neurology: a pilot study. GMS Z Med Ausbild. 2013;30(2):20.

21. Huitt TW, Killins A, Brooks WS. Team-based learning in the gross anatomy laboratory improves academic performance and students' attitudes toward teamwork. Anat Sci Educ. 2015;8(2):95-103.

22. Isbell JA, Makeeva V, Caruthers K, Brooks WS. The Impact of TeamBased Learning (TBL) on Physician Assistant Students' Academic Performance in Gross Anatomy. J Physician Assist Educ. 2016;27(3): $126-130$.
23. Martínez EG, Tuesca R. Modified team-based learning strategy to improve human anatomy learning: a pilot study at the Universidad del Norte in Barranquilla, Colombia. Anat Sci Educ. 2014;7(5):399-405.

24. Vasan NS, DeFouw DO, Compton S. Team-based learning in anatomy: an efficient, effective, and economical strategy. Anat Sci Educ. 2011;4(6):333-339.

25. Koles PG, Stolfi A, Borges NJ, Nelson S, Parmelee DX. The impact of team-based learning on medical students' academic performance. Acad Med. 2010;85(11):1739-1745.

26. Inuwa IM. Perceptions and attitudes of first-year medical students on a Modified Team-Based Learning (TBL) strategy in anatomy. Sultan Qaboos Univ Med J. 2012;12(3):336-343.

27. Burgess AW, Ramsey-Stewart G, May J, Mellis C. Team-based learning methods in teaching topographical anatomy by dissection. ANZ J Surg. 2012;82(6):457-460.

28. Huang Z, Li M, Zhou Y, et al. Modified team-based learning in an ophthalmology clerkship in China. PLoS One. 2016;11(4):e0154250.

29. McMullen I, Cartledge J, Levine R, Iversen A. Team-based learning for psychiatry residents: a mixed methods study. BMC Med Educ. 2013;13:124.

30. Ghorbani N, Karbalay-Doust S, Noorafshan A. Is a team-based learning approach to anatomy teaching superior to didactic lecturing? Sultan Qaboos Univ Med J. 2014;14(1):e120-e125. 


\section{Supplementary materials}

\section{Questionnaire for the effects of the}

\section{anatomy course}

\begin{tabular}{ll}
\hline Items & Description \\
\hline Communication ability & Whether your communication with the teachers or students is enhanced \\
Expression ability & Whether your language skill is enhanced \\
Generalization ability & Whether your generalization ability is boosted \\
Collaboration ability & Whether your cooperative ability is improved $\quad \square B ; \quad \square$; \\
Knowledge extension & Whether your scope of knowledge is expanded $\quad \square$ B; $\square$; \\
Learning initiative & Whether your learning initiative is increased \\
Classroom atmosphere & Whether the atmosphere in anatomy class is activated
\end{tabular}

Note: A: agree; B: disagree; C: neither agree nor disagree.

\section{Publish your work in this journal}

Advances in Medical Education and Practice is an international, peerreviewed, open access journal that aims to present and publish research on Medical Education covering medical, dental, nursing and allied health care professional education. The journal covers undergraduate education, postgraduate training and continuing medical education including emerging trends and innovative models linking education, research, and health care services. The manuscript management system is completely online and includes a very quick and fair peer-review system. Visit http://www.dovepress.com/testimonials.php to read real quotes from published authors.

Submit your manuscript here: http://www.dovepress.com/advances-in-medical-education-and-practice-journal 